\title{
The Humanities Computing Center and Library Collaboration in New Scholarly Communication Processes
}

Written for publication in Advances in Librarianship, vol. 26 (2002). [POSTPRINT]

by Jennifer Vinopal

Librarian for French and Italian Language and Literature

Coordinator of The Studio for Digital Projects and Research

Bobst Library

New York University

70 Washington Square South

New York, NY 10012

e. jennifer.vinopal@nyu.edu

v. 212.998 .2522

f. 212.995 .4583

\section{The Digital Revolution and the Library}

\section{A. Questioning Libraries and the Academy}

It is commonplace now to say that the digital revolution is changing the nature of librarianship and the role of the library in higher education, and thus creating new challenges for librarians. Even a partial list of recent concerns is daunting: new pricing schemes for electronic content, asynchronous and synchronous distance services, the growing use of metadata, the rising cost of serials, the transition from "just-in-case" to "just-in-time" (and even "just-for-you") collecting, the effect of licensing restrictions on traditional library services, etc.

While recognizing the challenges posed by our increasing creation, collection, and use of digital resources and the evolving role of the library in the academy, most experts reassure us that libraries retain their time-honored mission as collectors and guardians of the information scholars need to do their work. "What scholars want from librarians of the future is not so different from what they have wanted all along - the full range of resources they need to do their work" (American Council of Learned Societies/Council on Library and Information Resources, 1999). "Libraries are and will remain central to the management of scholarly communication for the foreseeable future" (Okerson, 1992). According to the results of a 1998-99 international survey on the role of the academic library in the year 2005, "The primary goal of the library will remain the responsibility for building of collections suitable for its parent institution" (Feret and Marcinek, 1999).

Yet how can this reassurance be reconciled with what we see, statistically, as grave challenges to the centrality of the library's basic services to its academic 
community: declining gate counts, declining circulation figures, decreasing use of print resources (including stacks collections and print reserves), plus the significant drop nationwide in reference statistics? Plus, when we do communicate with our users, we perceive that their expectations of library services have changed dramatically. However, how to respond is unclear because "we do not really know what university and college administrators and faculty want or expect the library to contribute to the institution's mission" (Troll, 2001).

In other arenas, the importance of the library to the mission of the academy is also being called into question, and librarians and their allies have been put on the defensive. A lecture by Nancy Kranich, Past-President of the American Library Association, was called "Why Do We Still Need Libraries?" The title of a position paper of the Association of College and Research Libraries (ACRL) asks "Do We Need Academic Libraries?" The report takes its title from a question asked in 1999 to library directors at member institutions of the Middle States Commission on Higher Education. The query was prompted by the controversial issue facing the commission of the accreditation of transregional and virtual institutions (Hardesty, 2000). As one can imagine, the ACRL report went on to answer with a firm "yes." As the possibilities of digital technology continue to push the boundaries of our definition of the academy, no part of the academy, no matter how intrinsically valuable we think it, will remain unquestioned.

At the same time, similar challenges to the academy are posed by technophiles and Luddites alike. David F. Noble cautions against "technological fetishism" in the "current mania for distance education" and warns of "the commodification of higher education" (Noble, 1999). On the other hand, John Unsworth, in responding to Sven Birkerts's The Gutenberg Elegies, writes about resistance to change and the "electronification of scholarly communication" in the academy, saying "the defenders of traditional academic practices find themselves in strange collusion with both the traditional and the emergent enemies of intellectualism" (Unsworth, 1996). These trends of commodification and anti-intellectualism in the academy hit the humanities particularly hard, as the humanities, more than the sciences and social sciences, are subject to criticism for their irrelevance to "real life."

To think critically about the state of libraries and the academy in the electronic age, it is important to first distinguish the content we supply (knowledge, services, etc.) from how we access or deliver them. And, while it would be naive to believe that the latter will not in some way affect the former (and vice versa), they should still not be confused or taken one for the other. Doing so often results in overinvesting the medium with a significance that rightfully belongs on the side of the content. The subsequent fetishizing or demonizing of the medium itself inhibits a clear analysis of the content's value. We first need to consider whether, regardless of new methods of delivery, we still believe in the value of the content (knowledge) we provide. Only then can we ask: What is the best way to provide students with what we consider a worthy education? 


\section{B. Librarianship: A Job and a Profession}

So, too, in the library there is an essential difference between the core mission and goals of our profession (our "content") and the daily jobs we do as librarians in order to deliver the value of our mission to our users. This distinction may seem too obvious to dwell on. However, at work and in the library literature, one often sees a conflation of the two. Librarianship as a profession (like many others) embodies a core set of beliefs or values. The ALA's draft statement on core values lists

connection of people to ideas; assurance of free and open access to recorded knowledge, information, and creative works; commitment to literacy and learning; respect for the individuality and the diversity of all people; freedom for all people to form, to hold, and to express their own beliefs; preservation of the human record; excellence in professional service to our communities; formation of partnerships to advance these values (ALA Core Values Task Force, 2000).

On the other hand, librarianship as a job is made up of tasks, projects, and services that are physical, time-based manifestations of these core values. Understanding this distinction means not allowing ourselves to be trapped into thinking that, for example, user education equals in-house bibliographic instruction, collection development equals merely buying and storing books and journals, knowledge management equals maintaining the card catalog, and reference assistance is acquired by visiting a reference room and talking to a librarian who sits behind a desk. In these four examples, I purposely chose an obviously outdated equation to make my point. Yet, one can certainly find contemporary examples that fit the equation. The resistance in some quarters to radically rethinking the traditional reference model comes to mind.

Seeing the usefulness of our basic services called into question, some have expressed a desire to secure our jobs in the future by discovering how to better implement those services (through, for example, a better or different use of digital information technologies). However, while it may provide some impetus to understand and adapt usefully to changes in our user community, this rather reactive approach seems to me to be more a symptom of our comfort with the status quo than a real compulsion to understand the evolving relationship between the library and the academy in the first place. If we are concerned about our usefulness to and future role in the academy (and the future of the academy itself), and we believe our core values remain legitimate, our goal should be to discover how to apply those values in ways useful to our users. This we can only do by examining and understanding the changes affecting the academy and our user community's functioning within it.

The role of the librarian has traditionally been limited to assistance with the research process: collecting, organizing, and preserving research materials, providing reference services, teaching bibliographic instruction classes, etc. There is currently 
widespread interest in reexamining the instructional side of the librarian-faculty relationship (the collaboration of librarians with faculty to improve the information literacy skills of students, supporting the use of classroom technology, and so on) but little parallel investigation of potential librarian roles in the other half of faculty's academic activity: scholarly communication.

In this article, I examine one segment of the academic library's user community - humanists - and one aspect of their intellectual activity within the academy - the scholarly communication process - in order to discover if and how the library can better support this group. (In this study, the term "humanities" will be used in a broad and purposely imprecise sense, to mean the arts, humanities and related disciplines.) I focus specifically on the new challenges and opportunities presented to humanists by digital technology, and provide an overview of the issues involved in establishing a Humanities Computing Center in order to support humanists' needs in this area. Finally, I suggest that, to take on potential new roles in facilitating the humanities scholarly communication process, librarians need to develop new competencies and skills, and the library organization as a whole needs to consider some fundamental changes to adequately support these new responsibilities.

\section{The Evolution of Scholarly Communication in the Humanities}

\section{A. How Humanities Scholarly Research and Communication Processes Are Changing in an IT Environment}

New types and increased availability of information technology resources are having an enormous impact on scholarly research and communication processes. Some of these changes, particularly in the areas of access and budgets, are readily visible and familiar to those working in libraries. A few examples suffice: quick, easy access to catalogs and databases; at colleges and universities with the financial means, the availability to the scholar of "free" digitized primary source materials (be they licensed or locally created); ease of scholarly communication at all levels, from e-mail to Web publishing; wider and faster access to materials through interlibrary loan. Of course, the cost of this digital world (often hidden from the user) belies the "free for all" appearance of library resources: it will cost more money, not less, to publish (and thus will cost more to acquire these materials); money must be made available for the equipment and technical support to enable scholarship; costs of content and delivery mechanisms are prohibitive for many libraries; preservation and archiving add greatly to overhead; etc.

Less obvious to librarians but equally fundamental to the evolution in scholarly communication are the changes in work patterns due to the adoption of information technology. Although the humanities still lag behind the sciences and social sciences in integrating computing into the research process, now, because of the increasing availability of relatively easy-to-use and affordable tools, humanists are becoming more reliant on and comfortable with many different types and 
applications of this technology. As they see the potential for exploitation in a given context (for example, the growing use of classroom technology for everyday teaching needs), humanities scholars are beginning to understand how this technology can be used to solve their own research problems. And, as more scholars avail themselves of electronic tools to exchange ideas (e-mail and, in particular, scholarly electronic discussion forums such as listservs), they are more likely to come in contact with, be influenced by, and even work more closely with scholars in other disciplines. Humanists' work is becoming more collaborative (or, in some cases, even teambased), and this work has a tendency to be more interdisciplinary. At the same time, scholars are gaining an understanding of methodologies that are different from the ones applied in their own fields, and fields of study are adapting to this crossfertilization of methods. These changes can be seen in, among other things, curriculum modifications in programs and departments, increased joint faculty appointments, and the growth of interdisciplinary studies in humanities publishing. Although these changes are not entirely due to the digital revolution, the increased availability of IT on campus has helped open the doors to sharing and overlapping among the disciplines.

Many also claim that working with computers in itself has a fundamental impact on the way humanists think about and organize their research. Computers "make explicit what in the past has been done intuitively; the preparation of data in a logical, formalized manner is an intellectually informative task and can reveal types of evidence and questions that would not otherwise have emerged" (Pavliscak et al., 1997). In 1996, John Unsworth suggested that the object of study itself might change due to the new types of research possible using computers.

$[\mathrm{W}]$ e can expect to see increasing interest in editing (including the theory of editing), in bibliographic and textual scholarship, in history, and in linguistic analysis, since these are areas in which the new technology opens up the possibility of re-creating the basic resources of all our activities and providing us with revolutionary tools for working with those resources.... [E]ven at its more formal, more filtered levels, electronic scholarly communication still retains the quality of making present that which was hitherto remote, difficult to access, and generally impossible to recontextualize (Unsworth, 1996).

Technology not only permits new ways of communicating and discovering, it makes possible new forms of presentation. The library literature on the relationship between scholars and technology focuses almost exclusively on the use of electronic research resources and rarely acknowledges the question of humanists as creators of digital material. But while the academy's emphasis is still primarily on the print monograph in the humanities, more and more academic publications are documenting an increasing interest in the idea of humanists as producers of digital materials or "e-projects." These new genres of communication and publishing look remarkably different from their print counterparts. 


\section{B. What Might New Scholarly Communication in the Humanities Look Like?}

Scholarly communication must not be confused with scholarly publishing, the latter being only a part of the former. Christine Borgman defines scholarly communication as "the study of how scholars in any field ... use and disseminate information through formal and informal channels. [It] includes the growth of scholarly information, the relationships among research areas and disciplines, the information needs and uses of individual user groups, and the relationships among formal and informal methods of communication" (Borgman, 2000, p. 414). In an IT environment, the more traditionally hidden (or nonpublishing) aspects of scholarly communication - personal communications, for instance - could potentially be integrated more easily into new forms of scholarly publishing.

Stanley Chodorow offers one view of the future:

While the traditional system of communication included private and public discourse ... the electronic environment unites and mixes these types and stages of communication. The use of the Web can put a private communication into the public domain. The publication of research results on the Web can be the basis for a set of comments and links to other results created by the participants in the research field. An electronic record of scholarship could grow organically as scholars make contributions to a database or to a series of linked databases that evolve as the collective work progresses" (Chodorow, 2000, pp. 90-91).

Robert Darnton's now famous model of what he calls the e-monograph combines a similar collection of heterogeneous yet related elements, both public and private:

I think it possible to structure it in layers arranged like a pyramid. The top layer could be a concise account of the subject, available perhaps in paperback. The next layer could contain expanded versions of different aspects of the argument, not arranged sequentially as in a narrative, but rather as self-contained units that feed into the topmost story. The third layer could be composed of documentation, possibly of different kinds, each set off by interpretative essays. A fourth layer might be theoretical or historiographical, with selections from previous scholarship and discussions of them. A fifth layer could be pedagogic, consisting of suggestions for classroom discussion and a model syllabus. And a sixth layer could contain readers' reports, exchanges between the author and the editor, and letters from readers, who could provide a growing corpus of commentary as the book made its way through different groups of readers (Darnton, 1999).

It is interesting to note that Darnton's model also capitalizes on the interdependence of research and teaching and is an example of how these two 
scholarly activities are, according to some, becoming less and less distinct in a digital environment.

Clifford Lynch identifies other new genres of scholarly communication not addressed by Chodorow and Darnton: network-based distributed seminars; collaborative research environments (or "collaboratories") that also document the research and knowledge creation process in order for them to be stored, reviewed, replayed, and annotated; instructional media systems; and Web sites as monographs and encyclopedias (Lynch, 1999).

Some scholarly publishing ventures are currently realizing visions such as Chodorow and Darnton suggest above, most notably the ACLS and Andrew W. Mellon Foundation's History E-Book Project (http:// www.historyebook.org/) and Gutenberg-e (http://www.theaha.org/prizes/gutenberg/), a joint venture of the Mellon Foundation, the American Historical Association, and Columbia University Press. In their effort to encourage experimentation with technology use in the humanities, both projects have as one of their goals the exploration of new methods and models for presenting scholarly knowledge in electronic form. They intend to look at issues such as alternative publishing models, the possible size and scope of such a publication, peer review, editing and production, types of content (e.g., inclusion of primary as well as secondary source materials), and the use and value of new forms of scholarship to the field.

\section{Disincentives to the Adoption of Digital Technology in the Humanities}

Although these well-funded projects offer potential models for future electronic publishing, and despite the growing exploitation in the humanities of ever more available technology, we mustn't underestimate the disincentives in the academy to the widespread adoption of digital technology in the humanities. The problems outlined in this section are particularly acute in those fields, which, unlike the sciences and more quantitative social sciences, don't have an extensive tradition of computer use in research and scholarly communication. One result of this disparity of IT use is that the institutional expectations of and commitment to supporting humanists' computing needs is much lower.

The authors of the 1997 ACLS report entitled "Information Technology in Humanities Scholarship" are careful in their discussion not to "give the impression that computer-based research in the humanities is thriving" (Pavliscak et al., 1997). In summarizing a 1998 U.K. study by the Arts and Humanities Data Service (AHDS) investigating "mechanisms for encouraging greater scholarly exploitation of information technologies and digital resources within the arts and humanities," Greenstein and Porter list in descending order of usage the digital information objects arts and humanities scholars are using. The first four are discovery and research resources: reference, secondary, and primary resources, and mixed media materials. In fifth place are "IT applications as a means of creating new kinds of information objects and artifacts (e.g. historical or archaeological simulations, digital art or performance pieces, etc.)" (Greenstein and Porter, 1998, pp. 147, 151). 
Disincentives to the adoption of digital technology in the humanities come in a variety of forms and from a wide range of sources, and the academic literature on the question has identified impediments as well as possible solutions. Academic institutions themselves take the brunt of the blame here, as they are in the ultimate position to facilitate or inhibit change within the academy. Without the encouragement and support of the institutions on which academics depend for their living, scholars are unlikely to risk exploring new methods of scholarly communication.

Where will the resources come from? Humanists need equipment, technical support, training, and time to learn and create. Access to computing and communications resources is less automatic for humanists than for computer scientists (American Council of Learned Societies, 1998), and this problem is even more acute for humanists at smaller institutions without the financial means of larger research universities. Typical project funding tends to be too short-term for the type of learning and work needed to create a digital project, and humanists, because of the nature of their research subjects, tend to be less able to leverage a commercial base than their science counterparts (American Council of Learned Societies, 1998). And whereas first-wave adopters of technology are usually self-taught experimenters, second-wave users will most certainly need even more encouragement, training, time, and ongoing support and services to make this transition.

The assessment and reward structure in the academy (tenure, promotion, raises, grants, awards) also discourages innovation. Uncertainty about peer review or other indicators of quality of the digital scholarly object creates a credibility problem for the scholar whose work relies heavily on information technology. How does a tenure committee, often composed of faculty unfamiliar with new technologies, assess the value of an electronic scholarly work created without a traditional peerreview process? A 1992 Mellon report recognized that "[a]ny new system will have to satisfy scholarly and institutional leaders that it is adequately peer reviewed and reliable before new types of publications can be rewarded. Until assurances of such rewards are in place, faculty will be reluctant to put their best work in new forms" (Okerson, 1992). Randy Bass is an unusual example in the humanities for having received tenure at Georgetown with a resume based in large part on work with new media technologies. In his 1999 plenary address to the American Association for Higher Education Forum on Faculty Roles and Rewards, he acknowledged that models for the successful negotiation of tenure based on electronic publishing are extremely rare. He introduced himself to the audience simply by stating "my primary qualification for addressing you today is that I'm still employed" (Bass, 1999).

Among others, the ACLS has also recognized that the lack of reward structure for innovation in the humanities has an added impact on new methods of scholarly investigation: "cross-disciplinary work is viewed with skepticism by many in academia, who fear that such work will not be rewarded comparably to intradisciplinary work, and that work involving development and implementation of systems may be stunted because of insufficient support for specialized implementation staff, documentation, evaluation, and other essential complements to 
the core intellectual work" (American Council of Learned Societies, 1998). Also, the creation of scholarly resources using digital technology, particularly in the absence of good publishing models, will require substantially more time than the average project destined for print publication and, in some cases, there may be no measurable outcome from such experimentation (Duffy and Owen, 1998, p. 184).

Thus, the status quo is remarkably attractive to humanists, especially untenured faculty. And ironically, younger academics who, more and more, are closer to or part of the generation weaned on information technology are the ones for whom this type of experimentation is most discouraged. Willard McCarty observed that "advances, such as the great Dartmouth Dante Database, have been made by senior academics, who can afford to take the risks incurred by investing significant time in such a new way of working. Their achievements are most admirable, but since they tend not to need anyone's permission, the basic institutional commitment tends not to be made" (McCarty, 1998).

Scholarly societies have a part to play in encouraging scholars and academic institutions to favorably view research using and creating electronic resources. The MLA, for instance, has sessions at its annual conference on humanities computing and has issued guidelines regarding faculty work and digital resources: Guidelines for Evaluating Work with Digital Media in the Modern Languages (Modern Language Association: Committee on Information Technology, 2001a); Guidelines for Institutional Support of and Access to IT for Faculty Members and Students (Modern Language Association: Committee on Information Technology, 2001b); and Revision Plan for the Guidelines for Scholarly Editions of the Committee on Scholarly Editions (Modern Language Association: Committee on Scholarly Editions, 2001). These types of statements by scholarly societies, in conjunction with a commitment to address the problem of peer review and quality assurance (like that attempted with the History E-Book project and Gutenberg-e, discussed earlier) may yet have an effect on the reward structure in the academy.

Additionally, in order for computing in the humanities to flourish, scholars also need more information about standards and best practices, and examples of successful projects in their research areas. They need to become familiar with the world of digital resources in their subject area, to consult with colleagues and with other computing experts to plan and carry out their ideas, and to learn from others' mistakes. And, if they want their digital research resources to have a longevity and usefulness outside of their own immediate needs, they have to be able to design resources that can potentially interact with other like projects, which means an additional emphasis on cooperation and conformity with other projects out there in the world. Although there are already good national and international mechanisms for sharing information on digital projects - such as the Digital Library Federation (DLF) and the National Initiative for a Networked Cultural Heritage (NINCH) - academic institutions still need to provide the infrastructure and support to facilitate this sharing of information. 


\section{Some Solutions}

Sarah Porter creates a four-tiered model of support that arts and humanities scholars require before they can effectively exploit digital technology in their research and scholarly communication: information (about resources, their creation and use, etc.), training, high-quality data resources, and a reward structure offering professional incentives to use or create digital resources in research and teaching (Porter, 1998, pp. 193-194).

Some academic institutions are addressing these needs by incorporating humanities computing into their curricula. An increasing number of schools are modifying or creating positions within "traditional" humanities departments that incorporate humanities computing into the job descriptions. Other institutions (particularly in the United Kingdom) are addressing these needs by making humanities computing a discipline in its own right as part of the humanities curriculum at the college and graduate level. Willard McCarty makes the case that humanities computing - what he calls the yenta among disciplines - should become part of the academy because of its fundamental interdisciplinarity and what, methodologically and even philosophically, it can offer the other disciplines.

The fundamental pragmatic reason for locating humanities computing within the institution as an interdisciplinary scholarly activity in its own right is rooted in the fact that from the computational perspective of data and explicit procedures, the arts and humanities overlap methodologically to a very high degree. Humanities computing reveals a substantial common ground of technique from which to address research and teaching problems across the disciplines. ... Humanities computing is by nature in everyone else's business, and thus a communal instrument for the probing and strengthening of community (McCarty, 1998).

As a program of study, humanities computing can address all four needs mentioned by Porter: information (about resources, their creation and use, etc.), training, high-quality data resources, and reward structure. The curriculum provides the information and training, and outcomes of such study would be the creation of high-quality resources. That the field of humanities computing is, in some quarters, being recognized as such and included in some universities as an academic discipline is a step along the road toward an improved reward structure for this type of scholarly activity.

\section{New Roles for Librarians in the Humanities Scholarly Communication Process}

\section{A. The Humanities Computing Center}


Humanities computing is, by its very nature, a collaborative activity. Practically, no matter how well trained, funded, and connected a scholar is, she will need the help of others, both on campus and off, to realize her project. In order to create a welcoming environment for humanities computing activities, the institution needs to make ongoing and perhaps dedicated services available to humanities scholars, and to encourage the collaboration necessary for these types of projects. As they are already in the business of providing information services, two natural partners for such collaboration include campus computing units and libraries. Other potential partners include the scholar's own department or others in the institution, computer scientists, software developers, other ongoing scholarly projects, university presses, and national agencies.

How can university units whose mission it is to promote and support the use of IT on campus work to address some of the disincentives to the development of humanities computing outlined earlier? Is it appropriate for the library to take on a collaborative role in the humanities scholarly communication process? There is precedent for librarians working with faculty in the area of scholarly communication. Librarians helped to create the SPARC initiative, "a worldwide alliance of research institutions, libraries and organizations that encourages competition in the scholarly communications market" (SPARC, 2001). Librarians have been instrumental in this effort to counter the trend of ever-higher journal pricing and the SPARC effort has thus been able to provide scholars with alternative, high-quality scholarly publishing venues.

James Neal, Columbia University Vice President for Information Services and University Librarian, encourages entrepreneurship and innovation in the academic library, which he sees as

both a historical archive and a learning and research collaboratory....

Academic libraries will become centers for research and development in the application of technology to information creation and use. They will become aggregators and publishers, and not just consumers of scholarly information. They will function as campus hubs for working with faculty on the integration of technology and electronic resources into teaching and research.

And he adds: "The framework for academic library participation in the learning and scholarly communication processes must be rethought, and new structures for promoting library partnerships with faculty are essential" (Neal, 2001, pp. 1-2, 7).

As noted in Section I, the role of the librarian has traditionally been limited to assistance with the research process - collecting, organizing, and preserving research materials, and providing reference services. In order to take on the new entrepreneurial and collaborative responsibilities imagined by Neal, librarians will have to learn to think of themselves as true partners and even, in some cases, as agents of change in the scholarly communication process (the SPARC initiative being a good example). This will be a difficult mindset to adopt for a profession that has tended to perceive its role as properly reactive to the needs of the users it serves. And 
it will take strong leadership to create an environment in which current roles and services can be thoroughly questioned and new ways for the library to carry out its mission can be imagined, tested, and implemented.

Libraries are, in fact, particularly well suited to partner with humanists interested in incorporating information technology into their scholarly communication activities. Of Porter's four areas of support needed to encourage arts and humanities computing - information, training, high-quality data resources, and a reward structure - libraries can and do contribute directly to the first three already. Our core values as librarians - connection of people to ideas, free access to information and knowledge, a commitment to learning - apply here even as the research and publishing environment we work in evolves. In order for librarians to take on new roles as collaborators and even agents of change, we need to better understand what we can bring to collaborative work in humanities computing and how to prepare ourselves for this work.

Humanities computing can occur in many places and in many ways: on the scholar's office or home computer, in a departmental lab, via e-mail, using commercial or home-grown resources or a combination of both, or on or off a network. It can involve using previously existing resources, repurposing other digital materials, digitizing analog resources, or creating entirely new research materials. But how can a scholar imagining a potential project find the breadth of information and tools needed to plan and realize a viable, functioning, and durable digital resource? On more and more campuses, university support for humanities computing is manifested in the creation of a Humanities Computing Center (HCC), where "scholars use computing tools in the pursuit of their research (e.g., text analysis), and in creating new scholarly and artistic works (musical compositions, thesauri, scholarly editions, etc.)" (Jerome McDonough, personal communication, July 2001). The HCC consolidates many disparate resources and services, providing equipment, materials, staff expertise, and knowledge in one location. They can provide a solution to the "treasure hunt" many scholars experience when seeking information and support for their IT needs.

HCCs vary considerably in their mission and goals, the equipment and services offered, location on campus, the ability of staff to support faculty projects, the number of projects that can be handled at a time, the involvement of the staff in national or international initiatives, and so on. Differences are dependent on such factors as budget, staffing, equipment, the facility's mandate, reporting lines, ongoing university or division-wide administrative support, and even intangibles such as how the facility has evolved over time because of use, which subset of the potential user community actually avails itself of the facility, or the types of projects being done. However, all HCCs function within a network of preexisting campus IT and information services, and most benefit greatly from collaboration with these units.

To supplement the scant professional literature on the question of potential roles for librarians in an HCC, I spoke to six professionals in the area of scholarly computing to determine what practitioners in the field thought about the ways librarians are working to facilitate scholarly communication in the electronic 
environment. Though my goal in this article is to focus on the humanities, a broader approach to information gathering on this topic is beneficial in order to put ideas about computing and scholarly communication in other disciplines at the disposal of those interested in supporting and encouraging computer use in the humanities. I therefore did not limit my interviews solely to people involved in humanities computing. The last part of this article makes extensive use of ideas and quotes from my conversations with Sayeed Choudhury (Hodson Director, Digital Knowledge Center, Sheridan Libraries, Johns Hopkins University); Jim Duncan (Coordinator, Information Commons \& Electronic Services, Hardin Library for the Health Sciences, The University of Iowa); Carol Hughes (Director, Collections Management, Questia Media, Inc., formerly Interim Director, Information and Research Services, The University of Iowa); Ron Jantz (Data Librarian, Alexander Library, Rutgers University); Jerome McDonough (Digital Library Development Team Leader, Elmer Holmes Bobst Library, New York University); and Daniel Pitti (Project Director, Institute for Advanced Technology in the Humanities, Alderman Library, University of Virginia).

\section{B. What Librarians Bring to the Table}

There was a high level of agreement among the interviewees and the pertinent articles regarding the core areas of librarians' knowledge that are most useful in partnering on scholarly computing projects. Although librarians are not necessarily unique in possessing many of these skills, their education and training emphasize and inculcate these qualities as the very foundation of the profession. They fall into four general categories that represent knowledge of and concern with people, materials, access, and the wider scholarly perspective.

Librarians have a public service training and perspective and tend to have good communication skills. Their training and experience in the reference interview allow them to tease out details about the researcher's needs, and their understanding of user behaviors - how users search, access and use resources - enables librarians to select and use print or electronic materials appropriately in response to users' research needs. They are also familiar with pedagogical methods and have experience teaching.

Librarians also have a good understanding of the relationship of print to electronic resources and the unique advantages and disadvantages of each. They apply their knowledge of preservation and archiving to both the print and, increasingly, the electronic world. In addition, librarians have a great concern for questions of access: indexing, searchability, knowledge organization and representation, and the selection of materials, regardless of format, that are appropriate for the library's user community.

Our considerable experience in both the information and scholarly worlds is a valuable combination for the academic community we serve. We have an understanding of current library operations and the general library landscape, we take the long view on information creation, organization, and storage, and we are deeply concerned with and knowledgeable about issues of copyright, intellectual property, 
and fair use. In addition, as specialists ourselves in the scholarly disciplines in which we work, we can combine our understanding of the research methods and scholarly communication processes within a field of study with our knowledge of the world of research materials and processes, and, in particular, the digital projects and developments in that discipline.

Despite the wealth of knowledge and experience the library has to offer, in a digital world it is no longer reasonable to expect that the library will be able by itself to support all of the research needs of the institution. We are becoming more and more open to and dependent upon intrauniversity partnering with other units to accomplish new initiatives. Lippincott has observed that the increasingly networked information environment has had an effect on the relationships between librarians and information technologists, with a "move towards shared responsibility in conceptualization of projects, authority, [and] allocation of resources" (Lippincott, 1996). The usefulness of collaboration between libraries and campus computing units is so evident that many campuses are increasing collaboration across the board or, in some cases, even merging the units. Such reorganization may take at least three forms: administrative realignment of reporting and budgetary lines, collaborative realignment to provide greater working-level linkages, or blending realignment of the two units into a single, cohesive information services division (Dougherty and McClure, 1997).

\section{What Do Collaborating Parties Stand to Gain?}

Collaboration brings both difficulties and rewards of its own. Kate Nevins, in an article entitled "Partnerships and Competition," outlines some of the difficulties encountered when libraries partner with nonlibrary organizations. She says we're not accustomed to it; we don't all necessarily share common goals, values and culture; we can't assume that our partners don't compete with libraries or (if there are several partners) with each other; and we don't have the established infrastructure for working with nonlibrary partners (Nevins, 1997). Tensions often exist among campus partners with different cultures, for example, charging for services, different academic credentials of staff, different salary structures, differences in stature and status in the academic community, or the question of who will manage the information resources (Woodsworth, 1998, p. 30). There are also "different attitudes towards change, different levels of technological expertise, lack of understanding of the skills of other participants, [a] desire to control one's own resources, [and] the budget process" (Lippincott, 1996).

Benefits include the two units working together to stave off declining levels of support, develop user-oriented services, sustain growth and develop information and network services, get and share resources, negotiate with vendors (minimize cost and maximize access), coordinate the management of various units responsible for the information technologies on campus, find space on campus for workstations, and measure effectiveness of computing and information services (Woodsworth, 1998, p. 29). Other incentives include shared resources, expertise, ideas, and synergies, making 
new connections, and the creation of a critical mass (of people, expertise, resources, etc.), allowing libraries to do in partnership what they couldn't do alone (Nevins, 1997).

Two or more organizations or divisions pooling resources will, given a healthy and cooperative partnership, accomplish more than any one individually. Whether the HCC is a stand-alone unit on campus or a collaborative creation of preexisting units, in order to provide a high level of support to projects and grow with changes in technology, standards, and user need, it will by necessity be a place dependent on collaborative relationships within and outside of the institution. There are also significant implications for funding. For example, outside funding, often hard to come by for humanities projects, may be easier to attract when projects are realized collaboratively. Mary Shaw, of Carnegie Mellon University, observed that "there is a scale of funding in technology that, if we thought carefully and creatively, might admit an incremental funding for collaborative projects that could leverage the technology developments. Assuming genuine collaborations rather than shotgun weddings, this could provide a quite respectable level of funding for the humanities partner as an add-on to a large project" (American Council of Learned Societies, 1998). Here Shaw is talking specifically about humanities partnering with larger, better-funded computer science projects, but the same argument can be applied to partnerships among humanities projects: smaller projects joining other larger, wellestablished, and better-funded projects can leverage off of the experience and reputation of the larger partner. Such collaborations, often involving partners from outside the academic institution, need to be forged, negotiated, and realized with the assistance of local expertise. The Humanities Computing Center could be the ideal locus for such planning.

All interviewees agreed that on-campus collaboration is a fundamental way of accomplishing a digital project. Common on-campus partners in such a center are campus computing, libraries, and interested faculty (who may, for example, sit on a center's planning or advising committee). Other units that may have an ongoing or occasional affiliation include TV and media services, other computing centers, and interested departments or individuals. Each campus unit has its own area of expertise that it can bring to bear on a digital project, and the needs of each project will, of course, determine the nature of the collaboration formed to accomplish it. Jerome McDonough says: "The range of projects supported by HCCs is too extensive to make blanket pronouncements. The type of support required by one project might best be supplied by librarians; on another project, you may need significant technology support that would be better supplied by members of an IT staff." While there will be some commonalities among most projects, in this model, where partners and processes change depending on the needs of the individual project, the partnering relationship remains a work in progress. To be successful, this requires a great deal of flexibility within the administrative structure of the facility and a high level of communication among partners in the facility and on the project itself.

The scholarly materials themselves may provide the impetus to partner in nontraditional ways. Libraries are filled with the stuff that scholarly research is made 
of. Important archival source materials, frequently only available for in-library consultation, may be made available for digitization and thus integration into a scholar's digital project if it is a collaborative project between the library and the faculty member. The library benefits, too, as it can leverage its special collections in order to be included in interesting and potentially well-funded and high-profile digitization projects seeking to use those materials. And, with the right planning and care, the library's research collections could be enhanced by incorporating the digital content produced by its partners. Greenstein says: "That content has enormous educational and cultural value, but only if it is assembled into professionally managed collections, maintained over time, and made meaningfully accessible to other end users through online portal and other services." Additionally, some user communities "may be in a position to supply tools to a digital library service environment that can enhance that environment's functionality." As libraries invest more and more in digital library collections and services, "there will be significant pressure to measure performance and value of investment in terms of use. By engaging with user communities more effectively, libraries can inform investment decisions by anticipating their potential benefits (and beneficiaries, where some financial return on investment is sought)" (Greenstein, 2000, pp. 296-297).

\section{Collaboration Changes Processes and Products}

In discussing the location of the Institute for Advanced Technology in the Humanities (IATH) in the library, Daniel Pitti said that, despite the fact that it doesn't report administratively to the library, "... putting all of these people near one another fostered a great deal of collaboration and mutual support between them, especially as they began to build up and share expertise. Even though the models were different [between the units], there were certainly a lot of the same computer skills and understanding that were shared." Pitti goes on to describe the collaboration itself as an evolving thing that needs to be negotiated carefully by the parties involved. "We suddenly find that we really have to get much closer and work much more closely with one another, but that this is a completely new thing and we don't really know how to do it because we've never had to work quite this intimately with one another. So we're beginning to negotiate how to do that and to work out the politics of it on one hand, but also to work out what the standards requirements and systems requirements are on the other. But in the process of the negotiation, some functions that might have been done by one of those communities may in fact be taken over by others. The activities and functions could move between those groups as we work out over time exactly who's going to contribute what and how."

As the nature of collaboration changes - as skill sets grow and responsibilities shift - the nature of what is being collaborated on and its outcomes also change. For example, some libraries and HCCs are beginning to work with faculty and/or university presses to publish and archive the digital projects that have been produced on campus. In some cases, it is libraries that are becoming the "publishers" of homegrown digital projects, with librarians selecting locally created materials 
appropriate for their collections and the library providing access to that material like any other in its collection. Clifford Lynch warns that "[1]ibraries will need to take a much broader view of how they define the potential universe of materials that are candidates for acquisition and incorporation in their collections." And he adds that "[i]dentifying materials for potential acquisition will require a close, continuing and open-minded dialog and collaboration with working scholars" (Lynch, 1999). Some university presses are also starting to venture into digital publishing. In addition to the academic presses involved in the History E-Book and Gutenberg-e publishing projects, the University of Virginia in October 2001 announced that it will create the first electronic imprint devoted exclusively to publishing original, peer-reviewed digital scholarship in the humanities (not simply electronic versions of print books).

Whatever the model for "publication" followed, these digital projects are, more and more, being brought into the peer-review process of library selection and university press publication, and that means new exigencies regarding a whole range of issues that wouldn't necessarily be important were the project designed as a "oneoff" resource. Projects primarily intended to satisfy the individual needs of one scholar alone might tend to be quirky in design, treatment, scope, etc. For projects seeking a broader audience and greater longevity, other design issues need to be addressed: adherence to standards; choice of data formats; archival issues; stabilization of data; scope of project; commitment to a coherent overall design, fit, and perhaps even interoperability, with the rest of the projects in the field (what David Seaman calls creating projects that "play well with others"); etc. These considerations certainly apply for projects destined to become part of the library collection and maintained "in perpetuity," and project managers will need to collaborate with library staff who have expertise in these areas in order to create data that can be maintained and migrated over time. In addition, the funding implications of such decisions are great. Grant-funding agencies are looking for these issues to be addressed in grant applications to ensure that their money is properly spent on welldesigned, stable data that will last.

\section{E. Partnering Relationships}

As mentioned earlier, tensions that inhibit healthy partnerships between libraries and campus computing include their different cultures, different academic credentials and salary structures, differences in stature and status in the academic community, different levels of technological expertise, and a lack of understanding of the skills of other participants. However, librarians' training itself can help bridge some of these gaps. As information professionals, librarians' strength lies in what Biddiscombe calls the intermediary problem-solving role, as they "understand how the technology can be used to further the learning experience." He goes on to say, "It is here also that the very qualities demanded of information professionals in the context of the academic community are no less needed in the relationships between the differently qualified professionals in a hybrid team. The open problem-solving approach is equally necessary for effective teamwork in the learning support 
environment" (Biddiscombe, 2000, p. 78). Over time, team members sharing goals, skills, knowledge, and experiences will make them less dissimilar and should ease those tensions. In fact, Lippincott recognizes that the traditional division of complementary skills into "content" for librarians and "conduit" for computing professionals is becoming blurred (Lippincott, 1996).

It is undeniable that this blurring of traditional roles and the mutual respect necessary for teamwork in an IT environment cannot be achieved without good communication and an openness to understanding the professional goals and expertise of other partners. However, to be (and to be perceived as) real assets to a team working on digital projects, librarians need to have a better set of computing skills than would otherwise be necessary working in a more traditional - though networked - library setting. Jim Duncan suggests:

One way that the librarians can get credence is for them to get as much expertise as possible in the kinds of technologies that the computing people are already knowledgeable about. I'm not suggesting that librarians become programmers. But it seems to me that one reason that we [at the Information Commons] have been able to play nicely with others in the field here on campus is because we've really proven that we've got technical chops and we've been able to produce some things that are significant and we've earned their respect. . . . And so they naturally think of us as partners now instead of those librarians who are kind of stuck in the mud and focused on text.

(The question of how librarians can improve their technical skills will be the focus of Section IV of this chapter.)

Interviewees had a range of reactions to the question: What is the nature of the relationship between the HCC staff and the scholars they are partnering with in order to accomplish these projects? How the relationships are imagined, formed, and function depends on many things, such as the nature of the facility, the services it provides, and its stated and actual mission. Carol Hughes suggests, "It's not a peerto-peer collaboration." Staff need to realize that "... this is [the scholar's] career, not yours. This is their tenure, this is their class, they're the ones that are really on the line. But in the other sense, it is very much the same kind of collaboration that you got when you approached faculty and talked them into letting you come into their class and do a BI. You tell them what the skills are and what you can add to their curriculum. And so you keep in mind: 'What is it they're trying to teach? What is their main message?"

For Daniel Pitti, how this relationship is defined depends on the mission of the organization. "The way we [at IATH] like to look at the Institute is that it is collaborative in nature. While it's driven by a particular faculty member's research interest, the intellectual work with respect to designing the system within which they're going to do their research is really done in collaboration with the institute staff and they're functioning as peers with the faculty member. We don't consider ourselves a service bureau as such, but as collaborators." 
The scholars using the facility will also bring their own expectations to the partnership, based, in part, on their knowledge about and relationship to the facility itself and its staff. Jim Duncan explains that when planning such a facility, "You need to have faculty involved. It was critical for the success of the [Information] Arcade the original concept - to have members of various faculty departments involved in casting that vision for what kind of facility would best serve them and I think what that also does is gets you immediate usage from those same faculty. If they feel like they've had what they want translated into reality they will come and use those facilities then." Working together as a team to realize a shared vision can thus promote a feeling of true partnership rather than a client/server relationship.

\section{F. The Location of the Humanities Computing Center}

Where on campus should these Humanities Computing Centers be located? While some might consider the library the most logical place for such a facility there is no consensus that this is the best solution. It can be argued that an administrative affiliation of such a center with the library is crucial because of the library's content and its longstanding commitment to pedagogy and research. However, one can also make the case that involvement in this type of scholarly activity has never been and should probably not be the domain of the library. Willard McCarty says:

Historically at least libraries have not gone beyond the provision of resources, 'electronic books' if you will, to the application of them in the pursuit of knowledge; such is not the role of the library and never has been. . . I suspect that nearly every library now has an "e-text" or multimedia centre, but as far as the question of this Seminar is concerned, that fact only marks the distinction between humanities computing and the resources with which to do it. I conclude that the library is in general not our natural home (McCarty, 1999).

According to some interviewees, having the HCC only loosely affiliated administratively with the library is a real benefit to the good functioning of the facility itself. According to Daniel Pitti, for such a facility to flourish in a library depends on how well the library's mission, as it is interpreted and carried out by the administration, tolerates a research and development work model and rhythm that differs substantially from the traditional library service model. He suggests that putting it administratively within a library will require not just new librarians but new University Librarians: "IATH, while it resides inside of Alderman Library, is not administratively part of it. We answer directly to the Vice President for Research. And it crosses the University's schools.... I think that physically [Humanities Computing Centers] do belong in libraries. Administratively, I'm not quite sure. I would say they do but only if the library culture can be expanded where they can exist within a hospitable environment. But I think it requires a certain amount of shift and accommodation away from traditional assumptions and models that are mass- 
production oriented and intolerant of research and failure." He compares IATH to the Electronic Text Center at the University of Virginia: "It administratively is within the library and it has much more of a traditional library service model. People come in and then there are people there who help them out and provide a service as such. And the Institute very clearly defines itself as being something different than that. So we have really two entirely different models."

Like IATH, the Scholarly Communication Center at Rutgers is located within a library but reports to the Director of New Brunswick Libraries. The staff at the SCC is given a good deal of latitude in choosing projects and how they accomplish them. Ron Jantz explains, "The Scholarly Communication Center is not involved in any of the real operational issues of either the library or campus computing and to me that is a very significant distinction. What that allows us to do is have quite a bit of freedom in launching new projects, in launching research or technology that might be useful to these digital projects. ... I believe the end result of this approach is severalfold: new technologies being made available to librarians and the library and new information sources that would not likely have been made available to R.U. and the public." And, echoing Pitti's concern for the time frame and experimentation necessary to realize digital projects, Jantz says, "I think it is very difficult to stimulate innovation when you are in an organization that puts a lot of pressure on dealing with the near-term, immediate problems."

McDonough says: "I don't think it's that important for humanities computing centers to be in or affiliated with libraries.... Certainly scholars may draw upon library resources in the course of these efforts, but that doesn't lead to any requirement that HCCs and libraries be bound at the hip. That being said, where HCCs exist on campuses separate from the campus library, it would be a very good idea for librarians to stay in regular contact with those centers to ensure that the materials they provide, both print and digital, are supporting scholars' work within the HCCs. And certainly the public service training and perspective that reference librarians employ in their work transfer well into providing support within a different context such as an HCC. So, while there's no strong reason for HCCs to be in or affiliated with libraries, there's also no strong reason why they shouldn't, and for some campuses, placing HCCs within the library may have benefits such as making noncirculating materials available to scholars within the HCC."

It is obvious at this point that, despite all of the advantages to librarian involvement in digital project creation and in staffing an HCC, the question of the library's ability to be a substantial and ongoing participant in the HCC is murky. Concerns raised earlier about the nature of library administration, its ability to support new work models and time scales for accomplishing projects in the digital realm, and the potential hindrances of restrictive reporting structures, in addition to practical considerations such as librarian release time and the acquisition of new skills, make one wonder about the practicality of really involving librarians in these endeavors. 
The issue of library subject specialist participation in a new computing facility came up during the planning process for the University of Michigan's Knowledge Navigation Center in the early 1990s. The question was:

While the traditional role of library subject specialists as partners in the scholarly process was one role the planning group pointed to time and again as reassurance that a new service unit had an obvious place in the library, it was also the source of one of the greatest challenges. How would such expertise be incorporated in any proposed facility? ... Lurking in the background was the obvious question: Would subject specialists be expected to 'put in time' or staff the facility? (MacAdam, 1998, p. 93).

It is not easy for libraries to give over the time and expertise of their staff to new computing endeavors. The Information Arcade is a collaborative effort of the University of Iowa Libraries, the Office of Information Technology, and the academic faculty and is designed to support the use of electronic resources in research, teaching, and independent learning. Libraries deal with content, supporting its selection, installation, use, and also the technical support for equipment located in the Arcade. The OIT manages the hardware and develops multimedia and instructional software (Lowry, 1994). However, the Information Arcade was staffed only with graduate students, and Carol Hughes says the Arcade seemed like "... a student-run auxiliary [to the library]. They were separate. If you staff it this way, and you don't have librarians in the facility who are also really integrated into the rest of the library, it becomes this other appendage. ... So I think it needs to be librarians [staffing such a facility] and it needs to be librarians who are really plugged into the rest of the crowd, and make sure it's not a little fiefdom on the side."

The Digital Knowledge Center at Johns Hopkins partners with the library on projects requiring the special knowledge and expertise of librarians, but the DKC has its own staff to accomplish projects. Sayeed Choudhury explains that in staffing a center, "You need to hire someone who can do this job, to manage the types of attributes or characteristics or skills that you're looking for. Don't worry about what the degree is. ... If you can find a librarian who can do the things you need to do, great, if you can find somebody else, fine. It doesn't really matter at this point. There's a lot of fluidity in terms of people's skill sets and what they can do. ... I do think that there are plenty of people in the library community who could fit into some of the things we're trying to do. But there are also people who have more nontraditional backgrounds who might be able to fit in. ... I think the real strength here is bringing in the computer science expertise when it's relevant and when it makes sense and having that rounded out or, if you will, maybe even driven in some cases by the other sorts of skills."

How will librarians participate in the activities of an HCC? As consultants? As staff? Will they be "borrowed" from a campus library or hired outright as employees of the HCC? If staff lines are shared between library and HCC, how will libraries alter work assignments to provide them that release time? How libraries and librarians 
might be involved in an HCC will depend on whether or not the library is willing and able to redefine how it accomplishes its mission vis-à-vis the academic world. Whatever the model for librarian participation (be it as full-time staff, consultants, through shared staff lines, etc.), what knowledge and skills will librarians need to acquire in order to be conversant with the issues and technology relevant to humanities computing?

\section{Professional Development Issues for Librarians}

\section{A. Personality, Knowledge, and Skills}

Although it is easy to create a wish list of recommended skills for librarians (or others) wishing to become involved in digital library or scholarly computing work, experts are careful to distinguish between three different types of qualities potential staff might possess: specific computing skills, a broader knowledge of issues and technology in the field, and particular behavioral or personality traits. As the traditional library and the digital library become less and less distinguishable from each other, the emphasis in library want ads is on the latter qualities rather than the former. Kimberley Robles Smith and Beverly P. Lynch compared library job advertisements appearing in College \& Research Libraries News for the month of March in 1983, 1988, 1993, and 1998. They concluded that recently "there was no tendency . .. to list numerous computer skills across the board. The most consistent computer related skills were broad and general. ... The requirement of behavioral traits also increased with time in these jobs. The earliest data emphasize skills, not behaviors . . ." (Robles Smith and Lynch, 1999, p. 269).

Their findings support Roy Tennant's suggestion that in hiring staff to work in a digital library environment, it is best to emphasize personality traits over skills. As change is the only constant, "it may be more productive to choose staff who can evolve as the needs of the organization change." Tennant suggests qualities to look for include a capacity to learn constantly and quickly, flexibility, skepticism, a propensity to take risks, a public service perspective, the ability to work with others, skill at enabling and fostering change, and the capacity and desire to work independently. And he states that "[a]nyone who exhibits [these traits] will be able to pick up whatever skill or experience is deemed necessary" (Tennant, 1998, p. 102).

Jim Duncan concurs and explains that when hiring staff for the Information Commons, "[w] hat I look for as a common thread is not that they already know the tools but that they have a sense of pedagogy, of scholarly communication processes, teaching, learning, user services ... those are the kinds of things I can't teach them because that's just exhaustive and some people just will never pick that up. But if they've already got those skills we can teach them the tools. We can expose them to the variety of technologies and media and then they start to apply those deeper lessons they've learned through their academic careers and they see the connection with the tools and then they start coming up with some very interesting ideas." 
Most interviewees and the relevant literature also emphasize the importance of having a familiarity with some of the broad knowledge areas pertinent to digital project work. These areas include a familiarity with intellectual property law, issues in electronic publishing, graphic and instructional design, the various media types (how they interact and can be delivered to the user), usability, cataloging and metadata, information retrieval, appropriate data and metadata standards for digital materials, and project management (including managing quality assurance).

As for specific skills, Tennant suggests staff have experience in imaging technologies, optical character recognition, indexing and database technology, programming, and Web technology. Other recommended basic computing skills include basic programming, basic markup languages, the basics of database design, and experience with digitization and multimedia technologies. Most often, however, these basic skills were considered important not in and of themselves, but because the specific information gleaned is generalizable to other situations. For example, though you may have no intention of ever becoming a programmer, taking a basic programming course to learn a structured programming language enables you to understand what computers can and cannot do, to know how much work is involved in making them do a particular task, and to communicate to a programmer the needs of the project at hand.

In addition, it is important to know about developments in scholarly communication and to keep up with what's happening in business, industry, and entertainment. Duncan suggests going to conferences not usually attended by librarians, such as Comdex, the Apple Worldwide Developers Conference, and Web publishing conferences. "I think it's valuable to see what's happening out in the industry and in entertainment, in business, and then take those lessons and bring them back to the library and figure out how we can run our own kinds of services, create our own kinds of materials, using those same kinds of tools and techniques." Choudhury recommends joining organizations such as the Association for Computing Machinery's special interest group on Computer-Human Interaction, which offers listservs, publications, and conferences.

The curricula of humanities computing programs provide an excellent idea of the nature and combination of skills and knowledge necessary for work in the field. Like the distinction among skills, knowledge, and personality traits discussed earlier, programs differ in the way they balance these factors. While some place heavier emphasis on the acquisition of technical skills, others take a more theoretical approach. For example, the University of Alberta's M.A. in Humanities Computing offers courses such as project design and management, computers and culture, knowledge management and analysis, computer tools for humanities teaching and learning, and multimedia for the humanities (University of Alberta, 2001). The Centre for Computing in the Humanities, King's College London, offers a B.A. minor and postgraduate classes in humanities computing. Course offerings include digital imaging, issues in electronic publishing, introduction to relational databases, and text analysis. And, the University of Virginia's new master's degree in Digital Humanities will provide hands-on computing experience and an historical background in 
computing, and it will cover cultural, theoretical, and even philosophical issues in humanities computing. In addition to courses such as information technology design and client-based approaches to developing software for the humanities, the program will also cover topics such as the critical issues and theoretical concerns that emerge from the intersection of humanities research and teaching with the tools and concepts of computational approaches to analysis and interpretation, and knowledge representation, whose topics include logic, philosophy of language, visual representation, bibliographic methods, information design, visual and textual models of epistemology, esthetics, and metaphysics of form.

Daniel Pitti suggests that this new program of study may also provide a model for librarian professional development in the area of humanities computing. "In some ways that's really a difficult and problematic thing at the moment. I think that Virginia is somewhat unique here in attempting to pioneer education in this area." $\mathrm{He}$ added that the new master's program "becomes sort of the prototype of a new form of education, a new discipline in some respects, and one which is influenced by, but also will probably influence, library education."

As discussed earlier in this article, it is commonly agreed that the knowledge and skills acquired in library education and training are desirable in an HCC. However, does it logically follow then that this is a natural activity for libraries to involve themselves in? Or, to go one step further, that library schools should be actively contributing to the formation of people prepared to work in teams to collaborate on discipline-specific computing projects? I have already said that how the first question is answered depends on whether or not the library and university administration see the goals of such a center as consistent with the mission of the library. How library schools respond to the second question depends on many things, not the least of which is the need to maintain enrollment figures in order to remain solvent. Simon Tanner observes that "[p]eople with the requisite mix of project experience and technical ability are in short supply for staffing digitisation projects at present ..." and says that training "will reap immediate benefits in terms of increased productivity and raised confidence." However, he sees shortcomings in current library school education and notes that "the management roles that librarians now fill are not covered in sufficient depth by our formal education process, for instance, project management and fundraising" (Tanner, 2001, p. 335).

Over the past decade, as many library schools sought to revitalize their curricula and prepare information professionals for an IT-rich future, there have been intense debates over the curricula of these programs, their names (to use or not to use the "L" word), and even the question of whether or not to maintain ALA accreditation. Some, like the University of Michigan's School of Information (which offers specializations in areas such as Human-Computer Interaction and Archives and Records Management), decided to drop the phrase "library and information science" from their names and broaden their scope to include computer science, the humanities, and social sciences. Others, like the University of California at Berkeley, opted to forgo ALA accreditation entirely to focus on information management issues. 
Daniel Pitti, referring to these changes in library schools, says, "In some ways I think some of those that are being most successful at redefining themselves and attracting students are those that are expanding their mission and taking on more things that have to do with the kinds of research that go on here [at IATH] - looking at the kinds of technology that are involved and beginning to develop courses around it." He offers as examples the University of Michigan, and the University of Washington's Information School. "I think those are the library schools that in fact are securing their future by doing this and recognizing that there is a clear trend within the humanities research community towards digitization and in order to continue that trend you have to have people that are trained and know how to work with the technology."

\section{B. Training Issues}

Assuming the library is to be affiliated in some way with the Humanities Computing Center, it is important to provide instruction or training for librarians appropriate for the extent of their involvement with the facility. (Of course, other staff also need to be trained, but as the focus in this section is specifically on librarians' professional development needs, nonlibrarian staff needs will not be directly addressed here). In order to properly integrate the HCC into existing services, it is likely that changes will need to be made to existing library procedures and policies in order to accommodate the new service. Thus, even those librarians not directly involved in staffing the facility or collaborating on humanities computing projects will need to be trained, to a greater or lesser extent. Training issues to consider include knowing what services the facility provides in order to properly refer potential clients (for example, from the reference desk), how to talk about the facility during faculty liaison activities, and collection development issues around content used or created in the HCC. Before this happens, however, the environment needs to be such that people feel comfortable with or, at the very least, receptive to this new service and to the changes it will mean for their daily jobs.

How does one overcome the natural resistance often encountered when introducing new services and encourage librarians to become knowledgeable, energized, and involved? In order to "buy into" and support a suite of new services or, as in the case at hand, a new affiliated facility that will undoubtably affect current library operations to a certain extent, staff first need to understand the reasoning behind the new endeavor. Information should be provided that answers basic questions: "Whom will it serve?" "How is it different from what we already do?" "Why is the library involved?" and "How will my job be affected?" Other potential questions include "If I want to be involved in project development, how can I find the time in my week to do so?" and "Will I be able to use the facility for my own work?"

When seeking to include librarians as partners in project development in the HCC (no matter what level of partnering you are hoping for) you need to target the right librarians for outreach and training and, if you sense reluctance, identify where it 
originates. Jim Duncan asks, "How do we identify projects that are in content areas that are of interest to particular librarians and then how do we get them comfortable with the technology? Oftentimes we can get them over the hurdle of this concept of changing their role easier if we can get them the training on the tools. I think a lot of the trepidation comes into play with 'I don't know how to use this software package. It's very difficult for me to learn this kind of thing on my own.' And so in bringing them into a team surrounding where it's real supportive, getting them the training hands-on that they need, giving them a lot of flexible time to explore and get comfortable with that, then they start to buy in to it much more readily."

Far from being irrational fears, a librarian's anxiety about technology might very well be motivated by entirely reasonable considerations. Library professionals are justifiably concerned about maintaining a mastery (and also the appearance of mastery) in their field when working with teaching faculty and other scholars. You need to be very supportive of tentative librarians, says Carol Hughes: "When you get with a group of people who are uncomfortable or don't feel they have the support and the technical expertise, they are concerned that they come off in an absolutely professional manner with the faculty when they're face to face. They have to feel very comfortable in their own skill set... Y You have to be really careful that they feel supported, so they don't feel overwhelmed and they don't feel stupid in front of the faculty." One particular motivation for librarians to learn new skills is if there is prestige to be gained through the activity. Carol Hughes relates how Iowa's Information Arcade and the Teaching With Innovative Style and Technology (TWIST) program developed a robust and well-attended training series. "The motivation for librarians to enroll in these classes derives in large part from the esteem in which TWIST [librarian-faculty] partnerships are held. The opportunity to work more closely with faculty from a new base of expertise that is so 'in demand' by the faculty is seductive" (Hughes, 1998, pp. 31-32).

However, any new service offered can be perceived as simply another addition to an already busy job, and this disincentive to become involved can have a cumulative effect if it causes feelings of resentment and has an impact on outreach and, eventually, service. Good time management skills can only go so far toward solving the problem of having too much work and not enough time. At some point, the situation needs to be acknowledged and addressed administratively. Duncan says, "What I've tried to do is figure out ways to help them find the flex time to be able to contribute on such projects. I've even battled on that kind of thing myself where I've said, 'OK, if I'm going to do this then I need to release this responsibility' and I get approval from my supervisors to do that and we get it reassigned to somebody. Because we can't always be going at this $120 \%$ rate - otherwise our end product will not be up to snuff. There are going to be things that get lost in the cracks. Sometimes there need to be hard decisions made about what we're willing to sacrifice here for the next 3 months. It may be that we cut back on a particular service and in exchange we're going to do this really innovative thing." How a library administration responds to this question is a measure of the library's true commitment to the endeavor. The success of such partnerships is dependent on the library's answer. 


\section{What Types of Learning Opportunities Can We Offer?}

Let us assume an encouraging environment with sufficient time and job flexibility for designated or self-selected librarians to undertake new professional commitments such as becoming affiliated in some fashion with a Humanities Computing Center. How and where should they learn, and who should teach them the new skills they will need? In addition to becoming involved in the organizations and conferences mentioned above, there are myriad workshops, seminars, and so forth on issues pertinent to work in humanities computing (to give just two excellent examples, the University of Virginia's Rare Book School's courses and the Northeast Document Conservation Center's School for Scanning). A subscription to the Humanist listserv alone will provide you with information about more workshops in the United States and abroad than one person could ever attend (Office for Humanities Communication [U.K.], 2001). In addition, for information professionals willing to take time off for postgraduate work, the University of Virginia is considering creating a postgraduate program in Humanities Computing that would offer individuals practical, full-time experience. Pitti explains: "One of the things we are toying with [at IATH] is the idea of putting together a 2-year postgraduate [which could be post-doctorate or post-masters] fellowship or residency where you bring in young graduates for a 2-year period to work within the Institute where they would learn more about the technology and working collaboratively with faculty members and the like. That would be one way of helping to educate and create the kind of people that employers seem to want."

However, a library committed to building a partnership with other campus units to create a collaboratively run HCC will also want to present learning opportunities closer to home in order to communicate to staff that it takes its commitment seriously and expects involved staff to be able to participate fully in the Center's activities. These opportunities can be organized by the library itself, or better yet, through the new facility. In creating the Knowledge Navigation Center at the University of Michigan, planners asked themselves, "How will library staff take on the roles required of them in the present and future academic library? Although envisioned as a public service unit, the planning group felt from the outset that, of all the purposes a new facility might serve, none was so critical as providing staff with a place to learn and experiment with new technology" (MacAdam, 1998, p. 96). Moreover, encouraging librarians to see the Center as a place to experiment and accomplish their own projects will automatically increase librarian comfort, interest, and involvement with the facility and ensure that it isn't viewed (suspiciously) as a unit disconnected from (and perhaps also drawing crucial resources away from) the rest of the library.

All sources consulted were skeptical or outright opposed to "just-in-case" teaching. One problem with such a method is that no one is ever quite satisfied with the result. Sayeed Choudhury says, "I think that you do want to be careful about audience, in terms of who this [training] is actually intended for. Everybody wants 
professional development at some level or another. And we have had cases locally where we have a professional development opportunity and because it's such a wide audience and a diverse group, some people leave saying ' $\mathrm{I}$ knew all that' and others end up saying 'boy I'm really overwhelmed, that was too much.' So the more specifically you can target the classes the more impact you might have."

Who trains is also an important question. When hiring trainers to come to the facility and train staff, Jerome McDonough says to exercise caution. "I guess my only real recommendation or caveat about [outsourcing] in-house training [rather than sending staff away to be trained] is that its biggest advantage is that it allows the training to be customized to your staff's needs. Take advantage of that, or it's probably not worth the money. Make sure that you're dealing with trainers who are willing to do some reasonably substantial work with you to elicit what the real training needs are and customize their training to your environment. Many training companies say they do that; within my experience, few do it well." If, instead, you opt to have Center staff do the training, Ron Jantz and Jim Duncan both acknowledge the strain it puts on limited staff resources, and this is all the more critical in facilities that are understaffed. In addition, the results of such training are questionable. The 1997 SPEC Kit on Electronic Scholarly Publishing acknowledges what most interviewees also felt, that "classroom training has drawbacks: most users will not retain much of what they learn unless they have to use it immediately, and training them in a specific tool may have limited value" (Soete, 1997, p. 14).

Duncan summarizes the drawbacks in organizing a staff-taught professional development program and suggests an alternative: "Well, there are two negatives: one is that it's going to consume a great deal of your time or whoever else is involved in planning and designing that training; second, there's the same kind of danger where the librarians who would be attending that training would get that hands-on experience but then would go back to their offices and their desks and they wouldn't ever follow through with actually implementing. Though from my perspective, if you identify projects - real-world opportunities - for them to use that training then you do it hand-in-hand, you get them the training they need and then they actually practice that through real-world projects."

Indeed, it was agreed that the best way to maximize the use of staff time, target an audience, teach specifically to their needs, and choose an appropriate learning model is by focusing on the moment of need linked to real-world projects. Hughes agrees that it is best "to have people who have this as a big chunk of their job so they have a reason to spend half a day every week doing it." Just as some libraries provide new employees with a partner or mentor to get them acquainted with the new work environment, libraries and HCCs can capitalize on in-house expertise by partnering employees working on projects in order to facilitate the transfer of immediately applicable knowledge within the organization. In this "Next to Nellie" approach, where an employee learns a new skill by sitting next to their more knowledgeable colleague (the hypothetical "Nellie") (Paterson, 1999), care should also be given to training the trainer to teach well, so the partnering relationship is a fruitful, not discouraging, one. 
With all the discussion about online education, and given the focus in an HCC on the network as a distribution method, it would seem appropriate to consider online learning, either through tutorials or an online class, in this discussion. The Metropolitan New York Library Council (METRO) organized a series of focus groups to discuss professional development needs in New York area libraries. According to the summary of these focus groups, participants identified the benefits of online learning as "the ability to do work at one's own pace, individualized attention, and the ability to complete the training without leaving one's workplace." The disadvantages were "the need for self-discipline of online learners" (Metropolitan New York Library Council [METRO], 2001, p. 4). On the other hand, the METRO group said that the benefits of classroom learning are "being away from the regular office environment and the spontaneity of the classroom. The ability to get away from the office provides participants with a break, allows them to network with others they don't know, and makes a clear statement that the course is part of the individual's job. In addition, interruptions are almost nonexistent" (Metropolitan New York Library Council [METRO], 2001, p. 4). Also, just as staff time may be taxed by in-house training, developing online tutorials or running an online class can also become extremely time-consuming. Hughes says that at Iowa they tried online tutorials, but determined that "[u]ntil we gain more experience with how faculty and staff use the tutorials it seems that personal instruction and ongoing 'facework' are required to support individual learning of new technologies" (Hughes, 1998, p. 32).

Of course, other local expertise should not be overlooked. Libraries or HCCs can also turn for help organizing professional development opportunities to other on-campus individuals, programs, or units with computing expertise and units or organizations within or outside of the institution that might assist with developing staff learning opportunities. Staff from other campus computing facilities could be asked to do training, run a series of workshops, or share their expertise through consultation on certain projects. Campus units such as New York University's Center for Teaching Excellence, whose goal is to organize development efforts throughout the University, could offer ideas, consultation, and play the role of matchmaker among potential institutional partners.

Regional library organizations can also be a good source of support in this area. The METRO focus group identified how an organization such as METRO can help individual libraries carry out training. They suggested that METRO provide training, assistance, or guidance for members who conduct or want to establish their own professional development programs, and that METRO could also act as a clearinghouse about the professional development activities taking place in METRO's member organizations, so that other members could participate (Metropolitan New York Library Council [METRO], 2001, p. 3).

\section{Conclusion}

This article was intended to be a broad overview of the issues concerning the creation of a Humanities Computing Center to support new IT-based methods of 
scholarly communication in the humanities, and the challenges posed to libraries by the creation of such centers. Throughout the article I raise many questions and provide few answers. The core dilemma underlying this discussion is: Should this type of endeavor be part of the library's mission? While this question can be investigated and debated at ground level, ultimately, of course, the answer must come from our leaders, who are in a position to interpret and change policy and to create institutional mandates. The best grassroots efforts to establish and maintain an HCC cannot be sustained without a substantial and ongoing commitment from the host or collaborating unit(s) and the university administration.

Answering "yes" will not be easy for libraries. If it is to be truly involved in supporting new forms of humanities scholarly communication, the library will need to move beyond the traditional distinction between the library as provider of information (us) and academics as creators of knowledge (them) and involve itself in efforts (both on campus and off) to partner with scholars and other information professionals to focus on activities that have not traditionally been part of the academic library's concerns. If the answer is "yes," library and university administrative support for these initiatives will have to come in many forms, including the creation of an appropriate reward structure for such work; recognition and encouragement of cross-disciplinary scholarship; flexibility in job assignments; organizational restructuring; budget; a commitment to lifelong learning of faculty and staff; and a recognition that the pace of work, its time lines, and its outcomes will be quite different from traditional research. In addition, to ensure that these initiatives are fully a part of the institution, library and university administrations will need to make clear to the entire organization that they are essential to the mission of the organization and to clearly articulate how and why, based on a commonly held understanding of that mission.

So many of the issues related to library support for humanities computing raised in this article remain to be studied at length. What is the impact of humanities computing and the HCC on "traditional" library activities (such as collection development, cataloging, and faculty liaison)? How are librarians actually working in and with HCCs (sharing staff lines? Part-time affiliation? Leaving the library world altogether?)? What types of reward structures have been developed for librarians affiliated with HCCs? How are faculty research and teaching activities being affected by developments in humanities computing? Examining these issues will shine more light on the humanities computing challenge facing academic libraries today.

\section{References}

ALA Core Values Task Force (2000). Librarianship and Information Service: A Statement on Core Values (5th draft). American Library Association, Chicago, http://www.ala.org/congress/ corevalues/draft5.html. 
American Council of Learned Societies (1998). Computing and the Humanities: Summary of a Roundtable Meeting (Occasional Paper \#41). American Council of Learned Societies, http://acls.org/op41-toc.htm.

American Council of Learned Societies/Council on Library and Information Resources (1999). Scholarship, Instruction, and Libraries at the Turn of the Century. Results from Five Task. Forces Appointed by the American Council of Learned Societies and the Council on Library and Information Resources. Council on Library and Information Resources, Washington, DC, http://www.clir.org/pubs/reports/pub78/contents.html, http://www.clir.org/pubs/reports/ pub78/pub78.pdf.

Bass, R. (1999, January 22). Discipline and publish: Faculty work, technology, and accountability. Paper presented at the AAHE Forum on Faculty Roles and Rewards, San Diego, CA, http://www.georgetown.edu/bassr/disc\&pub.html.

Biddiscombe, R. (2000). The changing role of the information professional in support of learning and research. Advances in Librarianship 23, 63-92.

Borgman, C. L. (2000). Digital libraries and the continuum of scholarly communication. Journal of Documentation 56(4), 412-430.

Chodorow, S. (2000). Scholarship and scholarly communication in the electronic age. Educause Review, 86-92, http://www.educause.edu/pub/er/erm00/pp086093.pdf.

Darnton, R. (1999). The new age of the book. The New York Review of Books 46(5), 5+, http://www.nybooks.com/articles/546.

Dougherty, R. M., and McClure, L. (1997). Repositioning campus information units for the era of digital libraries. In: Restructuring Academic Libraries: Organizational Development in the Wake of Technological Change (C. A. Schwartz, ed.), Vol. 49. ACRL, http://www.ala.org/acrl/pil/ pil49.html.

Duffy, C., and Owen, C. (1998). The view from the performing arts. The New Review of Academic Librarianship 4, 182-184.

Feret, B., and Marcinek, M. (1999). The future of the academic library and the academic librarian - A Delphi study. Paper presented at The Future of Libraries in Human Communication, Technical University of Crete, Chania, Greece, http://educate.lib.chalmers.se/IATUL/ proceedcontents/chanpap/feret.html.

Greenstein, D. (2000). Digital libraries and their challenges. Library Trends 49(2), 290303. 
Greenstein, D., and Porter, S. (1998). Scholars' information needs in a digital age: Executive summary. The New Review of Academic Librarianship 4, 147-156.

Hardesty, L. (2000). Do We Need Academic Libraries? A Position Paper of the Association of College and Research Libraries (ACRL) (Position Paper). Association of College and Research Libraries, http://www.ala.org/acrl/academiclib.html.

Hughes, C. A. (1998). "Facework": A new role for the next generation of librarybased information technology centers. Library Hi Tech 16(3-4), 27-35.

Lippincott, J. (1996). Collaboration: Partnerships between librarians and information technologists. Paper presented at the Networked Information in an International Context Conference, Heathrow, U.K., 9-10 February, http://www.ukoln.ac.uk/services/papers/bl/rdr6250/lippincott.html.

Lowry, A. K. (1994). The Information Arcade at the University of Iowa. CAUSE/EFFECT 17(3), http://www.educause.edu/ir/library/text/cem9438.txt.

Lynch, C. A. (1999). On the threshold of discontinuity: The new scholarly genres and the role of the research library. Paper presented at the ACRL National Conference, Detroit, MI, April 9, http://www.ala.org/acrl/clynch.html.

MacAdam, B. (1998). Creating knowledge facilities for knowledge work in the academic library. Library Hi Tech 16(1), 91-99.

McCarty, W. (1998). What is Humanities Computing? Toward a Definition of the Field [Web page]. McCarty, Willard, http://ilex.cc.kcl.ac.uk/wlm/essays/what/what_is.html.

McCarty, W. (1999). Humanities computing as interdiscipline. Paper presented at "Is Humanities Computing an Academic Discipline?” An Interdisciplinary Seminar, University of Virginia, Charlottesville, http://jefferson.village.virginia.edu/hcs/mccarty.html.

Metropolitan New York Library Council (METRO) (2001). METRO Professional Development Focus Group Analysis. Metropolitan New York Library Council (METRO), New York.

Modern Language Association: Committee on Information Technology (2001a). Guidelines for Evaluating Work, with Digital Media in the Modern Languages (Committee Report). Modern Language Association, http://www.mla.org/.

Modern Language Association: Committee on Information Technology (2001b). Guidelines for Institutional Support of and Access to IT for Faculty Members and Students (Committee Report). Modern Language Association, http://www.mla.org/. 
Modern Language Association: Committee on Scholarly Editions (2001). Revision Plan for the Guidelines for Scholarly Editions of the Committee on Scholarly Editions (Committee Report). Modern Language Association, http://www.mla.org/.

Neal, J. G. (2001). The entrepreneurial imperative: Advancing from incremental to radical change in the academic library. Portal $1(1), 1-13$, http://muse.jhu.edu/demo/pla/1.1neal.html.

Nevins, K. (1997). Partnerships and competition. Paper presented at the ACRL 8th National Conference: Choosing Our Futures, Nashville, Tennessee, 11-14 April, http://www.ala.org/acrl/invited/nevins.html.

Noble, D. F. (1999). Digital Diploma Mills, Part IV: Rehearsal for the Revolution [Web page]. http://communication.ucsd.edu/dl/ddm4.html.

Office for Humanities Communication (U.K.) (2001). Humanist Discussion Group [electronic seminar], http://www.princeton.edu/ mccarty/humanist/.

Okerson, A. (1992). University Libraries and Scholarly Communication: Synopsis (Study). Published by the Association of Research Libraries for the Andrew W. Mellon Foundation, http://etext.lib.virginia.edu/subjects/mellon/synopsis.html.

Paterson, A. (1999). Ahead of the game: Developing academic library staff for the 21st century. Paper presented at The Future of Libraries in Human Communication, Technical University of Crete, Chania, Greece, http://educate.lib.chalmers.se/IATUL/proceedcontents/chanpap/ paterson.html.

Pavliscak, P., Ross, S., and Henry, C. (1997). Information Technology in Humanities Scholarship: Achievements, Prospects, and Challenges-The United States Focus (Occasional Paper \#37). American Council of Learned Societies, http://acls.org/op37.htm.

Porter, S. (1998). Into the future: Scholarly needs, current provision, and future directions. The New Review of Academic Librarianship 4, 190-214.

Robles Smith, K., and Lynch, B. P. (1999). The changing nature of work in academic libraries. Paper presented at Racing Toward Tomorrow: Proceedings of the 9th National Conference of the ACRL, 8-11 April, 1999.

Soete, G. (1997). Transforming libraries: Issues and innovations in electronic scholarly publication. SPEC Kit 233, 1-39.

SPARC. (2001). The Scholarly Publishing and Academic Resources Coalition (SPARC), [Web site]. SPARC, http://www.arl.org/sparc/home/. 
Tanner, S. (2001). Librarians in the digital age. Program 35(4), 327-337.

Tennant, R. (1998). The most important management decision: Hiring staff for the new millennium. Library Journal 123(3), 102.

Troll, D. A. (2001). How and Why are Libraries Changing? [Draft] (White Paper). Digital Library Federation, http://www.clir.org/diglib/use/whitepaperpv.htm.

University of Alberta. (2001). M.A. in Humanities Computing at the University of Alberta, http://huco.ualberta.ca/.

Unsworth, J. (1996). Electronic scholarship or, scholarly publishing and the public. In: The Literary Text in the Digital Age (R. J. Finneran, ed.), University of Michigan Press, Ann Arbor, http://www.iath.virginia.edu/ jmu2m/mla-94.html.

Woodsworth, A. (1998). Computing centers and libraries as cohorts: Exploiting mutual strengths. In: Computing, Electronic Publishing and Information Technology: Their Impact on Academic Libraries (R. Downes, ed.), pp. 21-34. Haworth Press, New York. 